\title{
PREVALENCE OF EXTENDED SPECTRUM BETA-LACTAMASES (ESBLS) PRODUCING ESCHERICHIA COLI AND KLEBSIELLA PNEUMONIAE AMONG HOSPITALIZED PATIENTS FROM NIGERIA
}

\author{
Olivia Sochi Egbule and Bernard O. Ejechi
}

Department of Microbiology, Delta State University, P.M.B 1, Abraka, Nigeria.

Corresponding author's email; oliviaegbule@gmail.com; ejechiben@gmail.com

\begin{abstract}
The aim of this study was to determine the resistance patterns and ESBLs production among clinical isolates of Escherichia coli and Klebsiella pneumoniae in two government hospitals of Delta State, Nigeria. Urine, blood and wound samples were aseptically collected from hospitalized patients, bacteriologically processed and isolates identified using standard protocols. Antimicrobial susceptibility testing was determined by disc diffusion method. The plasmid DNA of Multidrug resistance (MDR) isolates were extracted by alkaline lysis method. Phenotypic ESBL production of the MDR isolates was done by Double Disc Synergy Test (DDST) while PCR was used to detect bla of which $161(74.2 \%)$ and 56(25.8\%) were Escherichia coli and Klebsiella pneumoniae respectively. The antimicrobial resistance varied from one location to another. All isolates obtained from blood of general hospital Warri (GHW) were 100\% resistant to amoxicillin clavulanic acid and the cephalosporins (ceftazidime, cefotaxime, and cefuroxime). Isolates from General hospital Agbor (GHA) showed high resistance of $75.0 \%$ to cefotaxime, $93.8 \%$ to each of ceftazidime and cefuroxime. Overall low resistance to nitrofurantoin was observed in E. coli isolates obtained from urine of GHW (27.5\%) and GHA (20.8\%). Out of 217 isolates, $75.1 \%$ (163/217) were MDR, of which $36.8 \%$ and $39.3 \%$ produced ESBL by DDST and PCR respectively. The most common ESBL gene was blactX-M expressed by $28(17.2 \%)$ of the isolates. The high prevalence of MDR and ESBL underscores the need for a continuous local monitoring of antibiotic resistance.
\end{abstract}

Keywords: antibiotics, Multidrug-Resistance (MDR), ESBL production, Klebsiella pneumoniae, Escherichia coli.

\section{INTRODUCTION}

Antimicrobial resistance (AMR) is increasing at an alarming rate despite the campaigns against AMR by numerous international and national health summits and conferences. The control and preventive measures taken so far have not stopped the global spread of resistance unlike other health issues. In a globalized world, AMR genes travel faster than ever before affecting every country irrespective of their level of income and development as resistant pathogens are no respecter of borders (O'Neill, 2015). The problem is more alarming in developing countries of Africa and particularly Sub-Saharan Africa. Several reports show that AMR is spreading fast in developing countries yet little is done to fight it, as gross abuse in the use of antimicrobial is still prevalent. Almost all antibiotics are available over the counter in most developing Sub-Saharan African countries and can be bought without prescription (Zaman et al., 2010; Essack et al., 2017). The 2014 World Health Organization (WHO) and the O' Neill (2015) report, identified Africa and East Asia as regions without established antimicrobial resistance surveillance systems. The situation is aggravated in Nigeria by delayed patients' presentation (due mainly to poverty), ineffective antibiotics and lack of laboratory capacity (O’Neill, 2015).

The intense use of antibiotics in hospitalized patients is an important factor promoting the emergence of multidrug resistance (MDR) in Sub Saharan-African countries, thereby leading to difficulties finding appropriate treatment and increased mortality and morbidity (Aly et al., 2008; Essack et al., 2017). The increase in the use of third- generation cephalosporin, fluoroquinolone and carbapenem over recent years has become a public health problem, creating a new burden on medical care in hospitals (Aly et al., 2008; WHO, 2018). A major issue in the increasing incidence of resistance in these antibiotics is the production of enzymes such as Extended Spectrum Beta-Lactamases (ESBLs). ESBLs are a group of plasmids mediated, diverse and rapidly evolving enzymes that enable bacteria possessing them to hydrolyze and thus confer resistance to Penicillin, extended spectrum cephalosporins, and monobactams (Fridkin et al., 2014; Fernando et al., 2017). ESBLs originate from point mutation in beta-lactam (bla)-encoding genes belonging to TEM and SHV types (Bush, 1989). Other widespread ESBLs are CTXM- Beta lactamases (Agyekum et al., 2016; Mahamat et al., 2019). The number of ESBL-producing Enterobacteriaceae has been on the increase in recent times worldwide (Bouchillon et al., 2004; Ghafourian et al., 2015; Shaikh et al., 2015) but more intense in developing countries (Pitout and Laupland, 2008; Muhammad and Swedan, 2015; Ogefere et al., 2015). Hospitalization has been identified as a major risk factor to express ESBL (Stadler et al., 2018) resulting in a corresponding multiple drug resistance and 
increasing clinical challenges (Bharat et al., 2006; Gargiullo, 2019).

Production of ESBLs is most common in gram negative organisms including Klebsiella pneumoniae, Escherichia coli, Proteus mirabilis, Pseudomonas aeruginosa, Salmonella, Citrobacter, and Shigella sp. (Ogefere et al., 2015; Barrios et al., 2017). According to a recent assessment, ESBLs producing $E$. coli and $K$. pneumoniae are one of the greatest threats to human health (WHO, 2017). Mobile element carrying ESBLs facilitate the dissemination of resistance determinants among different bacterial species via horizontal gene transfer mechanism permitting bacterial strains to spread far wider into niches previously inaccessible (Nordmann et al., 2002; Fang et al., 2008). The spread of such resistant bacteria among hospitalized patients in resource limited countries would have devastating effect considering the health infrastructure, lack of monitoring for microbial drug resistance, very low infection control practices and poor hygienic practices (Song et al., 2001; Yusuf et al., 2013). Gene transfer mechanisms allow mobilization of DNA fragments between plasmids and chromosomes (Vaidya, 2011).

In Nigeria, the magnitude of the problem associated with ESBL is still underestimated and not detected routinely in most clinical laboratories of government hospitals. The consequence of this is avoidable therapeutic failures in patients and increase in the potential for the emergence of MDR. Although there are a number of publications on detection of ESBL-producing bacteria causing clinical infections in many parts of the country (Yusuf et al., 2013; Iroha et al., 2009; Oluduro et al., 2014), little is known about ESBLs producing organisms in Delta State Nigeria. This study therefore, reports the resistance patterns, and prevalence of ESBLs producing clinical isolates of $E$. coli and $K$. pneumoniae obtained from two government owned hospital in Delta State, Nigeria.

\section{MATERIALS AND METHODS}

\section{Study sites}

Samples for this study were collected from two government owned hospitals; general hospital Warri and general hospital Agbor, both located in Delta State, Nigeria. These hospitals were selected because they serve as referral centers for thousands of people in these locations and environs.

\section{Ethical approval}

The institutional post graduate research board of Delta State University, Abraka approved this study, and consent from each participant or relatives in some cases was obtained before sample collection

\section{Sample collection and isolation}

A total of 600 wound, urine and blood samples were collected in 2014 from patients with wound, urine or blood infections admitted into two government owned hospitals of Delta State, Nigeria. One hundred of each sample type was collected from the two hospitals, making it a total of 200 samples for each sample type. Wound samples were collected aseptically using sterile swab stick while urine and blood samples were collected with sterile universal bottles. For urine and blood culture, blood agar (BA) and MacConkey agar (MA) was inoculated and incubated aerobically at $37^{\circ} \mathrm{C}$ for $24 \mathrm{hrs}$.

For blood culture, samples were first inoculated in tryptic soya broth to enhance microbial growth and incubated aerobically at $37^{\circ} \mathrm{C}$ for $24 \mathrm{hrs}$. Cultures showing signs of growth were sub-cultured into MacConkey agar for the isolation of Escherichia coli and Klebsiella pneumoniae. Sub-culture into blood agar was also carried out to further isolate Klebsiella pneumoniae. The plates were then incubated aerobically overnight. Blood cultures showing no sign of growth were followed up by examining the broth daily and doing a final sub-culture at the end of the $7^{\text {th }}$ day or at the appearance of turbid culture. Isolates were stored on nutrient agar slant at $4^{\circ} \mathrm{C}$ until further analysis.

Following incubation, culture plates were examined for bacteria colonies ad gram stained. Lactose fermenting isolates with colonial morphologies suggestive of Escherichia coli and Klebsiella species were subjected to Methyl Red (MR) and Voges-Proskauer (VP) tests and further identified by standard biochemical test such as indole test, motility, lysine decarboxylation, $\mathrm{H}_{2} \mathrm{~S}$ production, gas production, citrate utilisation and urease production (Barrow and Feltham, 1993).

\section{Antibiotic susceptibility profiles of $\boldsymbol{E}$. coli and Klebsiella pneumoniae}

Isolates were tested for their resistance profiles to commonly prescribed antibiotics by the kirby-Bauer disc diffusion method on Mueller Hinton agar (Oxoid, Hampshire, UK) plates as recommended by clinical laboratory standard institute (CLSI, 2012). Isolates from nutrient agar slants were inoculated into nutrient agar plates and incubated at $37^{\circ} \mathrm{C}$ for $24 \mathrm{hrs}$. A single colony was picked from the nutrient agar plate into 0.9 sterile saline water and the turbidity of the suspension adjusted to the $0.5 \mathrm{McF}$ arland standard. A $0.1 \mathrm{ml}$ volume of the $0.5 \mathrm{McFarland}$ _suspension was swabbed evenly on the surface of the Mueller Hinton agar plate. The surface of each plate was allowed to dry up before the antimicrobial disc (Abtek, Liverpool, UK) containing multiple antibiotics were placed on the surface of the agar. The plates were incubated at $37{ }^{\circ} \mathrm{C}$ for $24 \mathrm{hrs}$. The diameter of zones of inhibition around each disk were measured and interpreted according to CLSI guidelines 2012. Antibiotics discs used in the study and their concentrations are ceftazidime (CZ-30 $\mu \mathrm{g})$, cefuroxime (CR-

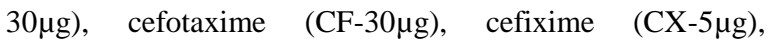
gentamicin $(\mathrm{G}-10 \mu \mathrm{g})$, amoxicillin-clavulanic acid (A-30 $\mu \mathrm{g})$, ciprofloxacin $(\mathrm{C}-5 \mu \mathrm{g})$, ofloxacin $(\mathrm{O}-5 \mu \mathrm{g})$, trimethoprimsulfamethoxazole $(\mathrm{S}-25 \mu \mathrm{g})$, and nitrofurantoin $(\mathrm{N}-300 \mu \mathrm{g})$. Multi drug resistance (MDR) among the isolates was defined as resistance to $\geq 3$ classes of antibiotics. E-coli ATCC 25922 was used as control.

Phenotypic Detection of Extended Spectrum Beta Lactamases

Double Disc Synergy Test (DDST) was used to detect the presence of ESBL phenotypically in MDR isolates (CLSI, 
2009). Mueller Hinton agar (Hi Media, India) was inoculated with 0.5 McFarland standard inoculum of the test isolate. Synergy was determined between test antibiotics (ceftazidime and cefotaxime) and the betalactamase inhibitor, amoxicillin-clavulanic acid, which was centrally placed at a distance of $15 \mathrm{~mm}$ apart from ceftazidime and cefotaxime. Enhancement of zone of inhibition by $\geq 5$ towards amoxicillin-clavulanic acid was interpreted as ESBL producer.

\section{Plasmid DNA Extraction}

Plasmid DNA extraction of MDR isolates was carried out by the alkaline lysis method of Birnboim and Doly (Birnboim and Doly, 1979). The extracted DNA were observed on $1.5 \%$ agarose gel. Electrophoresis was conducted on a horizontal gel apparatus for $45 \mathrm{mins}$ at $90 \mathrm{~V}$ using $500 \mathrm{~mm} 1 \mathrm{~mm}$ Tris Borate - EDTA (TBEXI) buffer (pH8.3). The molecular size of the plasmids was estimated by comparing with standard plasmids of known molecular weight.

\section{Molecular characterization of ESBL by PCR}

The most common genes coding for ESBL (bla $\underline{\mathrm{CTX}}_{\mathrm{C}}$, bla $a_{\mathrm{TEM}}$ and bla $\left.{ }_{\mathrm{SHV}}\right)$ genes were analysed by PCR in all MDR isolates using extracted plasmid DNA of MDR isolates and specific primers listed in Table 1. A $5 \mu$ DNA was used in $25 \mu 1$ reaction mixture containing $2.5 \mathrm{U}$ of $\mathrm{Taq}$ polymerase (thermo scientific, Germany), 200 $\mu \mathrm{m}$ each of dATP, dGTP, dTTP and dCTP, $0.2 \mu \mathrm{m}$ each primer, $1.5 \mathrm{mM} \mathrm{MgCl}_{2}$. PCR amplification conditions were: initial denaturation at $94^{\circ} \mathrm{C}$ for 10 minutes followed by 35 cycles of denaturation for $30 \mathrm{~s}$ at $94^{\circ} \mathrm{C}, 1$ minute of annealing at $56^{\circ} \mathrm{C}$, extension at $72^{\circ} \mathrm{C}$ for 1 minute and the final extension was done at $72^{\circ} \mathrm{C}$ for 10 minutes. The amplified products were visualized by ethidium bromide staining after gel electrophoresis in $1.5 \%$ agarose for 45 mins.

Table 1 Primer sequence

\begin{tabular}{llcc}
\hline Genes & Primer Sequences $\left(5^{\prime} \rightarrow 3^{\prime}\right.$ ) & Amplicons Size (Bp) & Reference \\
\hline SHV & F-TCAGCGAAAAACACCTTG & 471 & (Lai et al., 2007) \\
& R-TCCCGCAGATAAATCACC & & \\
TEM & F-CTTCCTGTTTTTGCTCACCCA & 717 & (Lai et al., 2007) \\
& R-TACGATACGGGAGGGCTTAC & & \\
CTX-M & F-ATGATGACTCAGAGCATTCG & 865 & (Nedjai, 2013) \\
& R-TGGGTTACGATTTTCGCCGC & & \\
\hline
\end{tabular}

\section{Results}

\section{Bacteria isolates.}

A total of 217 non-duplicate clinical isolates of E. coli and K. pnuemoniae from urine 108 (49.8\%), wound 61 (28.1\%) and blood 48(22.1\%) of government owned hospitals located in Warri (GHW- General Hospital Warri) and Agbor (GHA General Hospital Agbor) were obtained in this study (Figure 1). E. coli with an overall prevalence of 161(74.2\%) was more common than K. pnuemoniae 56 (25.8\%).

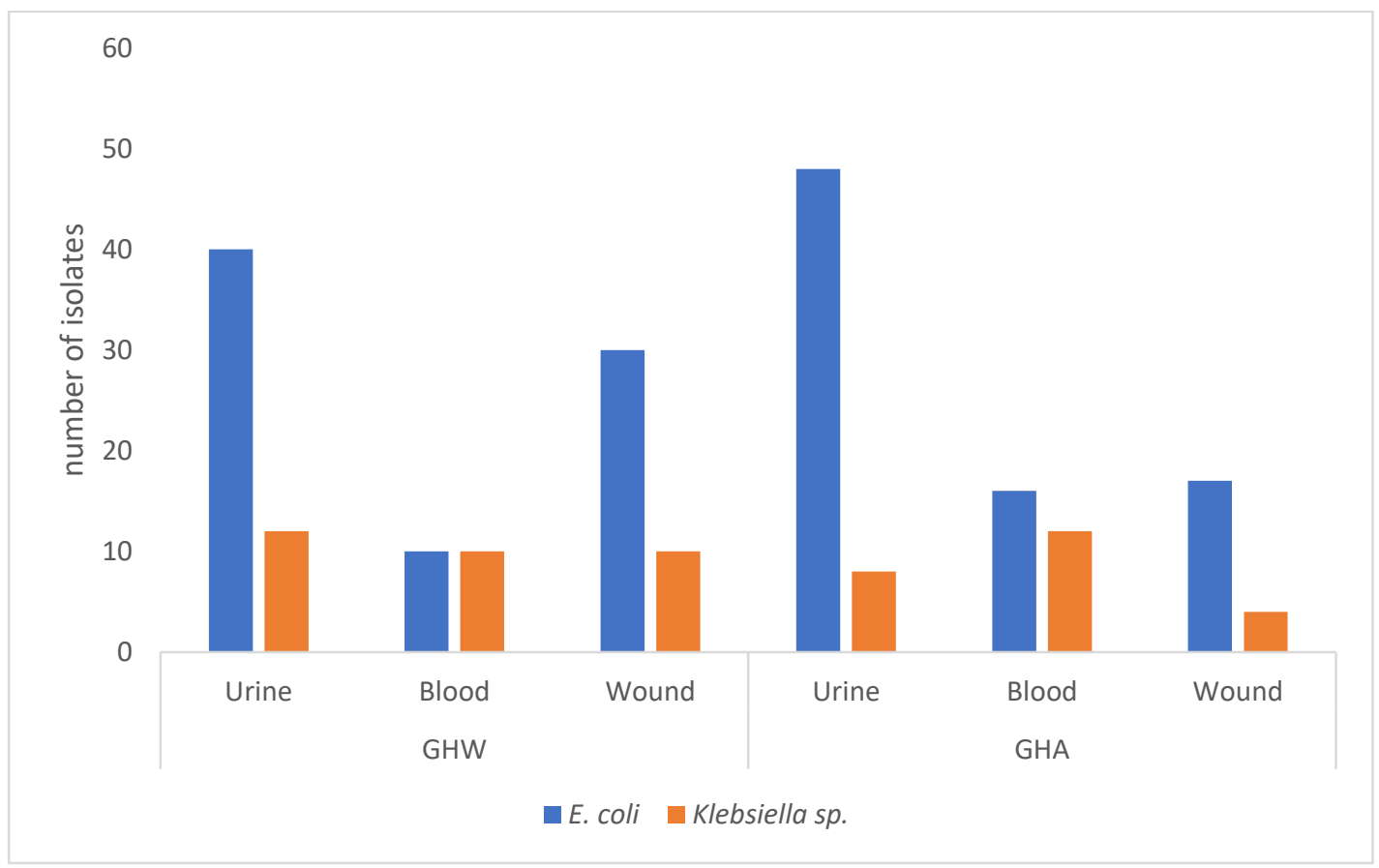

Fig. 1: Distribution of E. coli and Klebsiella pneumoniae 


\section{Antimicrobial resistance profile}

The antimicrobial resistance profiles of the 217 bacterial isolates obtained as shown in Table 2 revealed that resistance levels among the isolates varied from one location to another. A high prevalence of resistance was observed in amoxicillin clavulanic acid and the cephalosporins (ceftazidime, cefotaxime and cefuroxime). Cefixime was found to be a better option of the cephalosporins. In general, isolates from GHW exhibited higher levels of resistance to most of the antibiotics than isolates obtained from GHA. The pattern of resistance observed in the fluoroquinolones (ciprofloxacin and ofloxacin), gentamicin and trimethoprim-sulfamethoxazole were high and varied from one location to another. Variation was also observed in sample type. Isolates obtained from urine in GHW were more resistant to the fluoroquinolones than isolates obtained from GHA. Similar trend of higher resistance in isolates obtained from GHW was observed for gentamicin (Table 2). Overall low resistance to nitrofurantoin was observed, especially with $E$. coli isolates. 
Table 2. Susceptibility patterns of bacterial isolates from different government hospitals in Delta state

\begin{tabular}{|c|c|c|c|c|c|c|c|c|c|c|c|c|}
\hline \multirow[t]{2}{*}{ LOCATION } & \multirow[t]{2}{*}{ SAMPLES } & \multirow[t]{2}{*}{ ISOLATES(n) } & \multicolumn{10}{|c|}{ ANTIMICROBIAL AGENTS } \\
\hline & & & A & CX & CZ & CR & CF & G & 0 & C & $\mathbf{N}$ & $\mathbf{S}$ \\
\hline \multirow[t]{12}{*}{ GHW } & Urine & E. coli $(40)$ & 38 & 22 & 22 & 15 & 17 & 16 & 16 & 16 & 12 & 21 \\
\hline & & & $(95.0)$ & $(55.0)$ & $(55.0)$ & $(37.5)$ & $(42.5)$ & $(40.0)$ & $(40.0)$ & $(40.0)$ & $(27.5)$ & $(50.5)$ \\
\hline & & Klebsiella sp. & 12 & 12 & 12 & 12 & 8 & 6 & 6 & 2 & 2 & 5 \\
\hline & & (12) & $(100.0)$ & $(100.0)$ & $(100.0)$ & $(100.0)$ & $(66.7)$ & $(50.0)$ & $(50.0)$ & $(16.7)$ & $(16.7)$ & (41.7) \\
\hline & Blood & E. coli $(10)$ & 10 & 10 & 10 & 10 & 10 & 10 & 4 & 4 & 0 & 8 \\
\hline & & & $(100.0)$ & $(100.0)$ & $(100.0)$ & $(100.0)$ & $(100.0)$ & $(100.0)$ & $(40.0)$ & $(40.0)$ & $(0.0)$ & (80.0) \\
\hline & & Klebsiella sp. & 10 & 10 & 10 & 10 & 10 & 5 & 1 & 2 & 2 & 5 \\
\hline & & (10) & $(100.0)$ & $(100.0)$ & (100.0) & (100.0) & $(100.0)$ & $(50.0)$ & (10.0) & $(20.0)$ & (20.0) & (50.0) \\
\hline & Wound & E. coli (30) & 30 & 26 & 27 & 24 & 15 & 22 & 14 & 12 & 5 & 16 \\
\hline & & & $(100.0)$ & $(86.7)$ & (90.0) & (80.0) & $(50.0)$ & (73.30) & (46.7) & $(40.0)$ & (16.7) & (53.3) \\
\hline & & Klebsiella sp. & 10 & 10 & 10 & 10 & 10 & 10 & 8 & 8 & 2 & 1 \\
\hline & & (10) & $(100.0)$ & $(100.0)$ & $(100.0)$ & (100.0) & (100.0) & $(100.0)$ & $(80.0)$ & $(80.0)$ & $(20.0)$ & (10.0) \\
\hline \multirow[t]{12}{*}{ GHA } & Urine & E. coli $(48)$ & 35 & 21 & 35 & 29 & 16 & 14 & 14 & 14 & 10 & 15 \\
\hline & & & (72.9) & $(43.8)$ & (72.9) & $(60.4)$ & (33.3) & $(29.2)$ & (29.2) & $(29.2)$ & $(20.8)$ & (31.3) \\
\hline & & Klebsiella sp. & 8 & 7 & 7 & 4 & 3 & 0 & 2 & 0 & 2 & 6 \\
\hline & & (8) & $(100.0)$ & $(87.5)$ & $(87.5)$ & $(50.0)$ & $(37.5)$ & $(0.0)$ & $(25.0)$ & $(0.0)$ & $(25.0)$ & (75.0) \\
\hline & Blood & E. coli (16) & 16 & 13 & 15 & 15 & 12 & 11 & 3 & 3 & 2 & 13 \\
\hline & & & $(100.0)$ & $(81.3)$ & (93.8) & (93.8) & (75.0) & $(68.8)$ & (18.8) & $(18.8)$ & $(12.5)$ & (81.3) \\
\hline & & Klebsiella sp. & 10 & 9 & 9 & 9 & 3 & 7 & 3 & 4 & 4 & 3 \\
\hline & & (12) & $(83.3)$ & $(75.0)$ & (75.0) & (75.0) & $(25.0)$ & $(58.3)$ & $(25.0)$ & (33.3) & (33.3) & (25.0) \\
\hline & Wound & E. coli (17) & 15 & 12 & 15 & 11 & 12 & 12 & 9 & 10 & 3 & 4 \\
\hline & & & $(88.2)$ & $(70.6)$ & $(88.2)$ & (64.7) & $(70.6)$ & $(70.6)$ & (52.9) & $(58.8)$ & (17.7) & (23.5) \\
\hline & & Klebsiella sp. & 3 & 2 & 2 & 1 & 2 & 2 & 0 & 0 & 1 & 1 \\
\hline & & (4) & $(75.0)$ & $(50.0)$ & $(50.0)$ & (25.0) & $(50.0)$ & $(50.0)$ & $(0.0)$ & $(0.0)$ & $(25.0)$ & (25.0) \\
\hline
\end{tabular}

Key: A-Amoxicillin-Clavulanic acid; CX-Cefixime; CZ-Ceftazidime; CR-Cefuroxime; CF-Cefotaxime; G-Gentamycin; O-Ofloxacin; C-Ciprofloxacin; N-Nitrofurantoin; S-Trimethoprimsulfamethoxazole.

GHW-Government Hospital Warri; GHA-Government Hospital Agbor. 
Overall, 75.1\% (163/217) of the isolates showed resistance to at least three antimicrobials (MDR) with a higher number in $E$. coli 114 (52.5\%), However all $k$. pnuemoniae isolates obtained from Warri were MDR (Table 3).

Table 3: Prevalence of MDR bacteria among clinical samples

\begin{tabular}{|c|c|c|c|c|c|}
\hline \multirow[t]{2}{*}{$\begin{array}{c}\text { Location of } \\
\text { hospital }\end{array}$} & \multirow[t]{2}{*}{ Isolates } & \multirow[t]{2}{*}{$\begin{array}{c}\text { No. of MDR isolat } \\
\text { n }(\%)\end{array}$} & \multicolumn{3}{|c|}{$\begin{array}{l}\text { Prevalence of MDR bacteria in samples } \\
n(\%)\end{array}$} \\
\hline & & & Urine & Blood & Wound \\
\hline \multirow[t]{2}{*}{ Warri } & E. coli & $59(36.2)$ & $24(14.7)$ & $10(6.1)$ & $25(15.3)$ \\
\hline & K. Pneumoniae & $32(19.6)$ & $12(7.4)$ & $10(6.1)$ & $10(6.1)$ \\
\hline \multirow[t]{2}{*}{ Agbor } & E. coli & $55(33.7)$ & $30(18.4)$ & $13(8.0)$ & $12(7.4)$ \\
\hline & K. pnuemoniae & $17(10.4)$ & $6(3.7)$ & $9(5.5)$ & $2(1.2)$ \\
\hline Total & & $163(75.1)$ & $72(44.2)$ & $42(25.8)$ & $49(30.1)$ \\
\hline
\end{tabular}

\section{Plasmid profile}

Plasmid profiles of all MDR isolates analyzed revealed that out of the 163 MDR isolates, 141 (86.5\%) harbored plasmids of sizes $1.513 \mathrm{~kb}, 9.32 \mathrm{~kb}$ and $23.130 \mathrm{~kb}$. The number of plasmids carried by each isolate was also determined. Fifty-five (39.0\%) isolates contained 1 plasmid, $86(61.0 \%)$ contained 2 or more plasmids while $22(15.6 \%)$ MDR isolate had no plasmid. (Table 4). The prevalence of plasmids DNA varied from one location to the other. A higher prevalence of $79(56.0 \%)$ was observed in GHW, while $63(44.7 \%)$ was observed in GHA. It is notable that similar plasmids size of 23.130kbp was observed in all MDR isolate harboring plasmids originating from wound and blood of GHA.

Table 4: Prevalence of plasmids DNA among isolates

\begin{tabular}{lllllllll}
\hline $\begin{array}{l}\text { Number of } \\
\text { plasmids }\end{array}$ & & \multicolumn{3}{c}{ GHW } & \multicolumn{3}{c}{ GHA } \\
& Urine & Blood & Wound & Total & Urine & Blood & Wound & Total \\
\hline 1 & 12 & 06 & 11 & 29 & 26 & 0 & 0 & 26 \\
2 Or more & 23 & 14 & 13 & 50 & 10 & 14 & 12 & 36 \\
\hline Total & 35 & 20 & 24 & 79 & 36 & 14 & 12 & 62
\end{tabular}

Phenotypic and genotypic distribution of ESBLs among $E$. coli and $K$. pnuemoniae

The DDST phenotypic test for ESBL production, detected ESBL in 36.8\% (60/163) of MDR isolates. An overall 39.3\% (64/163) ESBL genotype comprising bla стХ-м, bla тем blashv genes were detected in 28(17.2\%), 26(16.0\%) and 10(6.1\%) of the isolates, respectively (Fig. 2). However, the prevalence of these ESBL genes varied with locations. bla

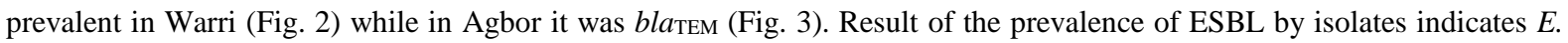
coli $(42 \%)$ as the higher producer of ESBL than $K$. pnuemoniae.

All ESBL producers were resistant to amoxicillin clavulanic acid and were also multi resistant to at least 6 or more antibiotics tested, including the cephalosporins, aminoglycosides, and trimethoprim-sulfamethoxazole. Additionally, all ESBL producer exhibited very low resistance rate to Nitrofurantoin (Table 5). 


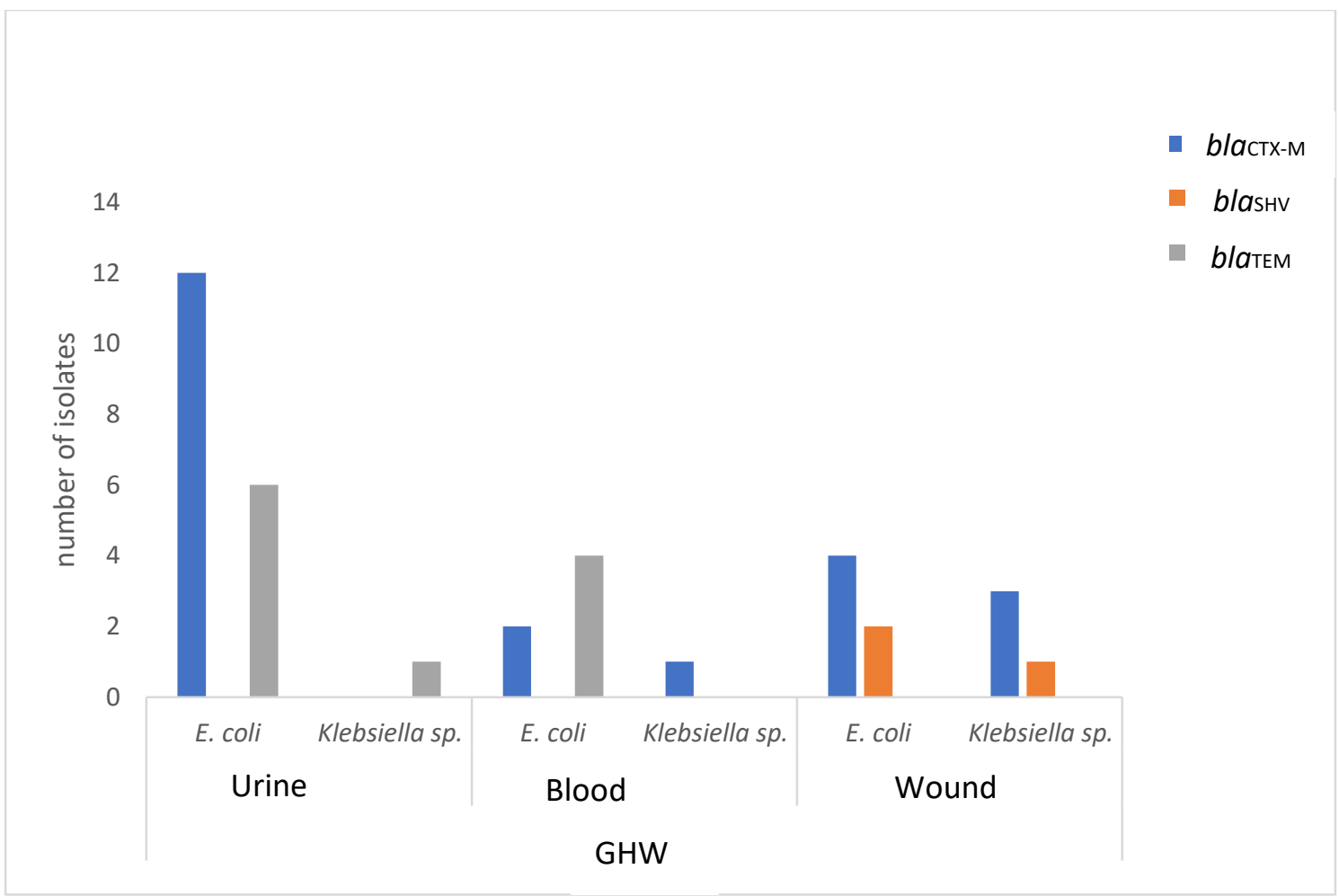

Figure 2. Number of E. coli and Klebsiella isolates from GHW producing ESBL

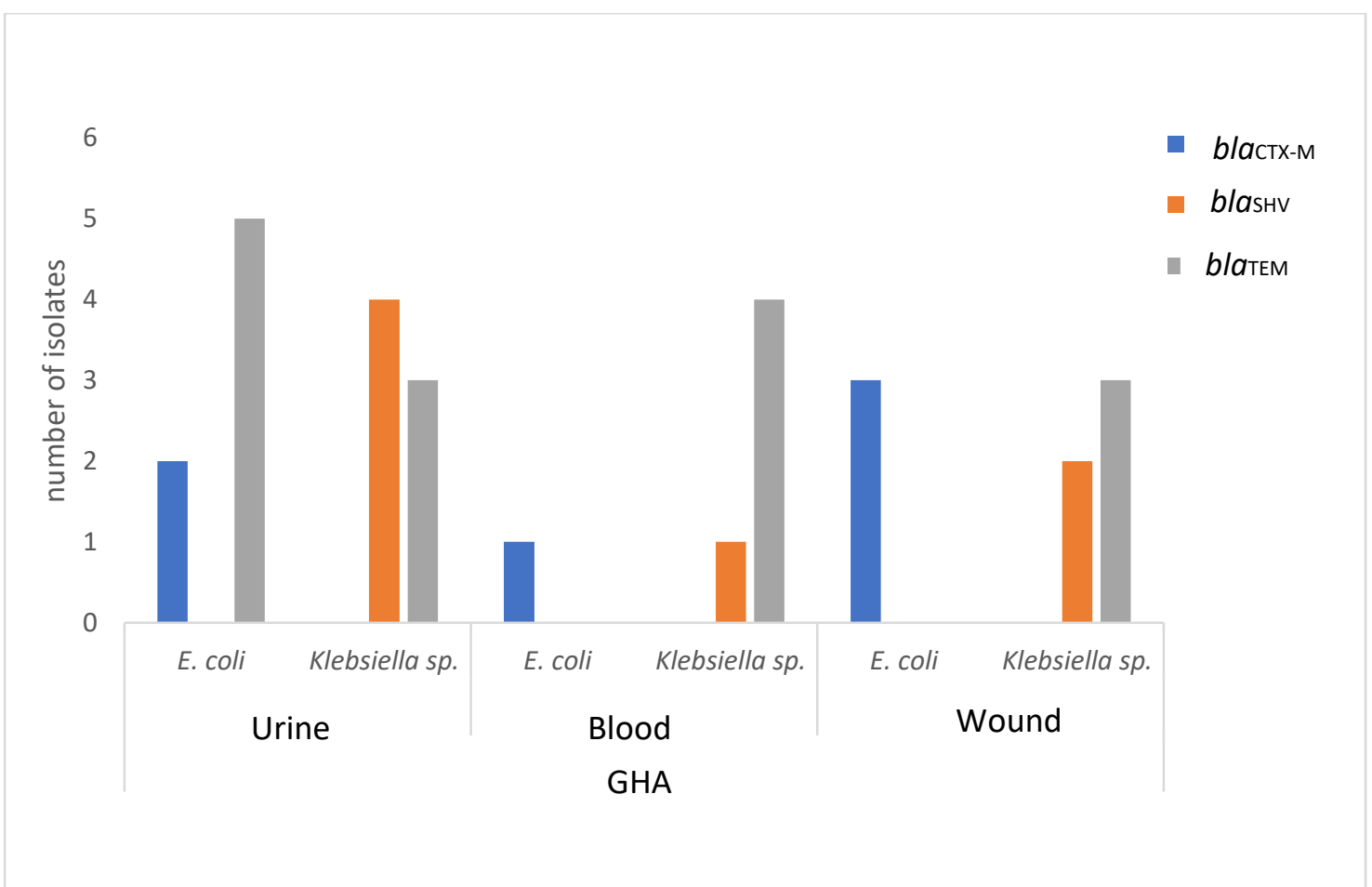

Fig 3. Escherichia coli and Klebsiella pneumonia isolates producing ESBL from GHA Table 5: Resistance pattern of ESBL producing isolates

\begin{tabular}{llll}
\hline & Antibiotics & E. coli & K. pneumonae \\
$\mathrm{N}=41$ & $\mathrm{~N}=23$ \\
\hline Class & Types & $\mathrm{n}(\%)$ & $\mathrm{n}(\%)$ \\
Penicillin & Amoxicillin-Clavulanic $(\mathrm{A})$ & $41(100.0)$ & $23(100.0)$ \\
Cephalosporin & Cefixime $(\mathrm{CX})$ & $34(82.9)$ & $18(78.2)$
\end{tabular}




$\begin{array}{llll} & \text { Ceftazidime (CZ) } & 37(90.2) & 21(91.3) \\ & \text { Cefuroxime (CR) } & 37(90.2) & 21(91.3) \\ & \text { Cefotaxime (CF) } & 37(90.2) & 21(91.3) \\ \text { Nitrofurans } & \text { Nitrofurantoin (N) } & 2(4.9) & 2(8.6) \\ \text { Aminoglycoside } & \text { Gentamicin (G) } & 24(58.5) & 15(65,2) \\ \text { Fluoroquinolones } & \text { Ciprofloxacin (C) } & 26(63.4) & 15(65,2) \\ & \text { Ofloxacin (O) } & 24(58.5) & 15(65,2) \\ \text { Sulfonamides } & \text { Sulfamethxazole-Trimethoprim } & 28(68.3) & 17(73.9) \\ & (\mathrm{S}) & & \\ & & \end{array}$

\section{DISCUSSION}

Surveillance of antibiotic resistance plays a major role in effective patient management, awareness creation and implementation of control measures. This is important in resource limiting countries of Sub-Saharan Africa such as Nigeria where unfortunately there is poor access to quality microbiology diagnostics, and lack of enforcement of infection control measures resulting in increased risk of morbidity and mortality from MDR (Essack et al., 2017; WHO, 2014). Antibiotics resistance, MDR profiles and prevalence of ESBL genotypes was described in this study.

The general antibiotic resistances observed in this study were high and varied. The variation may be attributed to the different sample origin (urine, blood and wound) of the bacteria studied. This perhaps affects the outcome of antibiotic therapy. Reta et al., (2019) also observed that resistance to antimicrobials can differ depending on the infection site.

High levels of resistance were observed in the fluoroquinolones, gentamicin and trimethoprimsulfamethoxazole. These drugs were among the most effective agents of choice in the empiric treatment of $E$. coli and most bacterial infections in the past decades (Zykov et al., 2016; Onanuga et al., 2019). Nitrofuratoin had the lowest resistance prevalence among $E$. coli isolates collected from patients with urinary tract infections (UTIs). Given that Nitrofurantoin exhibited low resistance prevalence of $<20 \%$, it would be prudent to consider it for empiric therapy in $E$. coli isolates causing UTIs. The International Disease Society of America (IDSA) and some authors (Warren et al., 1999; Gupta et al., 2011) have recommended the use of antibiotics for empiric therapy if the prevalence does not exceed $20 \%$. In line with the present study, the global rates of resistance of E. coli isolates causing UTI to nitrofurantoin are lowest (Bryce et al., 2016; Onanuga et al., 2019). Nitrofurantoin also demonstrated excellent activity against ESBL producing isolates. Over $80 \%$ of the isolates in this study were resistant to amoxicillin-clavulanic acid and cephalosporin antibiotics, which is attributable to the level of use in therapy for bacterial infection and the common use of beta-lactam antibiotics in the study area. This trend has been reported in other parts of the country (Iroha et al., 2009; Yusuf et al., 2013; Oluduro et al., 2014) and some Sub Saharan African countries of Tanzania (Kumburu et al., 2017), Ethopia (Muluye et al., 2014), Zimbabwe (Mbanga et al., 2010) and Rwanda (Carroll et al., 2016).

The prevalence of MDR observed in this study $163(75.1 \%)$ are similar with previous findings in Ethiopia (Teklu et al.,
2019). In addition, similar plasmids of $23.130 \mathrm{kbp}$ was observed in MDR isolates obtained from wound and blood of GHA. Plasmids may play an important role in the dissemination of resistance genes in the hospital. Most studies have shown that in clinical strains, ESBLs are commonly located on plasmid (Pai et al., 2001; Cao et al., 2002). These plasmids carry genes for resistance to multiple antibiotics. This is of concern as government owned hospitals in Nigeria are usually overcrowded thereby facilitating resistance gene transfer. Overcrowding is often worsened by minimal infection control practices as observed by the low standard of hand wash by both health care workers and patients during sample collection. With the lack of infection control and poor hygiene, resistant organisms may persist in hospitals environment where they easily acquire more resistant genes. Therefore, the hospital environment may serve as reservoir for resistant organism. Transfer of MDR between isolates from patients and the environment has been reported in some studies (Betteridge et al., 2013; Lesing et al., 2017; Kome et al., 2019). In most cases, admitted patients' rooms of government owned hospitals are not usually adequately cleaned making the patient's immediate environment sources of MDR. The high burden of MDR observed in this study coupled with the varied resistance pattern makes empiric antibiotic use challenging. Therefore, constant investigation of AMR pattern and surveillance programs could guide physicians on antibiotic usage and prevent the emergence and subsequent spread of MDR. In addition, early detection of resistance will reduce the potential misuse of antibiotics. However, to achieve the most effective empirical therapy, it is important to evaluate the local etiology and resistance patterns from time to time.

Inspite of the occurrence and continual spread of ESBL mediated beta lactam resistance, which is widely reported globally and in some hospitals in Nigeria, screening for ESBL production is not conducted currently in the laboratories of the two hospitals under study. As at the time samples were collected for this study, no laboratory in both rural and urban hospitals of Delta State routinely screen for ESBL production. First/second line treatment antibiotics such as ceftazidime and cefuroxime which are known to be hydrolysed by ESBL producers and were observed to be either totally resistant or slightly susceptible in this study are still routinely prescribed in these hospitals without susceptibility text results. The ESBL producing phenotype were detected in $36.8 \%$ of MDR isolates. This figure is comparable to the $39.8 \%$ reported by Iroya et al., (2009) in Enugu State, Nigeria. Other authors 
studying ESBL phenotypes in Nigeria also reported slightly lower and very high rates. A prevalence of $31.6 \%$ was reported in Abuja (Akanbi et al., 2013), 47.1\% in AkwaIbom (Azakhueme et al., 2015), 76.9\% in Ibadan (Okesola and Adeniji, 2010). Lower rates of $19.3 \%$ was reported by Yusuf et al., (2013) in Kano.

This study in addition characterized MDR bacteria from each hospital for bla $a_{\mathrm{CTX}}, b l a_{\mathrm{TEM}}$ and bla $a_{\mathrm{SHV}}$ genes by PCR. We observed that the most $(39.3 \%)$ prevalent bla gene among

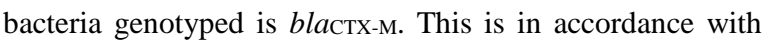
most previous results describing bla CTX-M $_{\text {as }}$ the most widely distributed ESBL genotype (Raji et al., 2015; Mahamat et al., 2019). The bla $а$ стХ-м type was also most common in E. coli which is consistent with previous results (Liu et al., 2009; Woerther et al., 2013). However, bla predominant ESBL group in Warri location while the common ESBL genotype at Agbor was_bla suggests diversity in epidemiological variation in predominance of ESBL genotype from different study location of this study. These differences observed may be because the bacteria were isolated from patients with diverse characteristics based on different antibiotics history, comorbidities with other diseases etc. It is also important to note that the hospitals sampled are referral centers and patients are from different geographical regions and human development index. These would affect the resistance pattern and thus cause the variation in ESBL genotypes observed from this study.

\section{CONCLUSION}

The present study reported varied resistance pattern and a high prevalence of MDR in clinical isolates of E. coli and $K$. pnuemoniae which may make empiric therapy and infection caused by these bacteria challenging. An additional highlight in this study with regards to ESBL is the differences in ESBL distribution which is an indication of the different hydrolysis capacity of the isolates. This should be considered in therapy. The production of ESBL in this study has drawn attention to the need for better diagnostic techniques in government hospitals of Delta State, Nigeria, a change in prescription patterns and ultimately the need for a surveillance system. These can lead to a reduction in MDR strain and a successful infection control.

\section{Acknowledgement}

We would like to thank the head, Microbiology Department, of Delta State University, Abraka Dr. O. E Nwafor for permitting us carry out part of the laboratory work in the department's laboratory. We also thank Mr Bright Igere for helping out with the molecular analysis.

\section{Authorship Contributions}

Data collection, processing and writing was by O.S Egbule. Supervision and critical review of the manuscript was by B.O Ejechi

\section{Conflict of interest}

The authors declare that they have no conflict of interest.

\section{Financial Disclosure}

This work was partly sponsored by Nigeria Tertiary Education Trust fund

\section{REFERENCES}

Agyekum, A., Fajardo-Lubián, A., Ansong, D., Partridge, S.R., Agbenyega, T. and Iredell, J.R. (2016). bla carried by IncF-type plasmids is the dominant ESBL gene in Escherichia coli and Klebsiella pneumoniae at a hospital in Ghana. Diagnostic Microbiology and Infectious Disease, 84: 328.

Akanbi, B., Ojonuba, B. and Njoku, R. (2013). Detection of Extended Spectrum $\beta$-lactamase Producing Klebsiella pneumonia and Escherichia coli in Two Hospitals in the Federal Capital Territory, Abuja, Nigeria. Journal of Medical Microbiology, 3(4): 207-212.

Aly, N.Y., Al-Mousa, H.H. and Al Asar, E.S.M. (2008). Nosocomial infections in a medical-surgical intensive care unit. Medical Principles and Practice, 17: 373-377.

Azekhueme, I., Moses, A.E. and Abbey, S.D. (2015). Extended Spectrum Beta-Lactamases in Clinical Isolates of Escherichia coli and Klebsiella pneumoniae from University of Uyo Teaching Hospital, Uyo-Nigeria. Journal of Advances in Medical and Pharmaceutical Sciences, 2(3): 117-125.

Barrios, H., Garza-Ramos, U., Mejia-Miranda, I., ReynaFlores, F., Sánchez-Pérez, A., Mosqueda-García, D. and Silva-Sanchez, J. (2017). ESBL-producing Escherichia coli and Klebsiella pneumoniae: The most prevalent clinical isolates obtained between 2005 and 2012 in Mexico. Journal of Global Antimicrobial Resistance, 10: 243-246.

Barrow, G.H. and Feltham, R.K.A. (1993). Cowan and Steel's Manual for Identification of Medical Bacteria. 3rd Edition, Cambridge University Press, Cambridge, pp-331.

Betteridge, T., Merlino, J., Natoli, J., Cheong, E.Y., Gottlieb, T., Stokes, H.W. (2013). Plasmids and bacterial strains mediating multi-drug resistant hospital acquired infections are coresidents of the hospital environment. Microbial Drug Resistance, 19: 104-109.

Bharat, P.M., Janak, K., Rajan, D.K., Shyam, M.K., Prem, K.K. and Tuladhar, N.R. (2006). Multidrug-resistant and extended-spectrum beta-lactamase (ESBL)-producing Salmonella enterica (serotypes Typhi and Paratyphi A) from blood isolates in Nepal: Surveillance of resistance and a search for newer alternatives. International Journal of Infectious Diseases, 10: 434-438. 
Birnboim, H.C. and Doly, J.A. (1979). Rapid alkaline extraction procedure for screening recombinant plasmid DNA. Nucleic Acids Research, 7(6):1513-1523.

Bouchillon, S., Johnson, B., Hoban, D., Johnson, J., Dowzicky, M. and Wu, D. (2004). Determining incidence of extended spectrum $\beta$-latamase producing Enterobacteriaceae, vancomycin-resistant Enterococcus faecium and methicillinresistant Staphylococcus aureus in 38 centres from 17 countries: the PEARLS study 2001-2002. International Journal of Antimicrobial Agents, 24(2): 119-124.

Bryce, A., Hay, A.D., Lane, I.F., Thornton, H.V., Wootton, M. and Costelloe, C. (2016). Global prevalence of antibiotic resistance in paediatric urinary tract infections caused by Escherichia coli and association with routine use of antibiotics in primary care: systematic review and metaanalysis. British Medical Journal, 15: 939-945.

Bush, K. (1989). Characterization of $\beta$-lactamases. Antimicrobial Agents and Chemotherapy, 33: 259-276.

Cao, V., Lambert, T. and Courvalin, P. (2002). COLEC1Like Plasmid PIP843 of Klebsiella pneumonia encoding extending spectrum beta lactamase (TXM-17). Antimicrobial Agents and Chemotherapy, 46: 1212-1217.

Carroll, M., Rangaiahagari, A., Musabeyezu, E., Singer, D. and Ogbuagu, O. (2016). Five-year antimicrobial susceptibility trends among bacterial isolates from a tertiary health-care facility in Kigali, Rwanda. American Journal of Tropical Medicine and Hygiene, 95: 1277-1283.

Clinical and Laboratory Standards Institute (CLSI) (2012). Performance Standards for Antimicrobial Susceptibility Testing; Twenty-Fourth Informational Supplement. CLSI Document M100-S22, Wayne, 32(1).

Essack, S.Y., Desta, A.T., Abotsi, R.E. and Agoba, E.E. (2017). Antimicrobial resistance in the WHO African region: current status and roadmap for action. Journal of Public Health, 39(1): 8-13.

Fang, H., Ataker, F., Hedin, G. and Dornbusch, K. (2008). Molecular epidemiology of extended-spectrum $\beta$-lactamases among Escherichia coli isolates collected in a Swedish hospital and its associated health care facilities from 20012006. Journal of Clinical Microbiology, 46(2): 707-712.

Fernando, M., Luke, W., Miththinda, J., Wickramasinghe, R., Sebastiampillai, B. and Gunathilake, M. (2017). Extended spectrum beta lactamase producing organisms causing urinary tract infections in Sri Lanka and their antibiotic susceptibility pattern- a hospital base cross sectional study. BMC Infectious Diseases, 17(1): 138.

Fridkin, S., Baggs, J., Fagan, R., Magill, S., Pollack, L.A. and Malpiedi, P. (2014). Vital signs: Improving antibiotic use among hospitalized patients. Morbidity and Mortality Weekly Report, 63(9): 194-200.

Gargiullo, L., Chierico, F.D., D'Argenio, P. and Putigiani, L. (2019). Gut microbiota modulation for multidrug resistant organism decolonization: Present and future perspectives. Frontiers in Microbiology, 10: 1704.

Ghafourian, S., Sadeghifard, N., Sohelli, S. and Sekawi, Z. (2015). Extended spectrum Beta-lactamases: definition, classification and epidemiology. Current Issues in Molecular Biology, 17: 11-21.

Gupta, K., Hooton, T.M., Naber, K.G., Wullt, B., Coigan, R., Miller, L.G., Morgan, G.J., Nicolle, L.E., Raz, R., Schaeffer, A.J. and Soper, D.E. (2011). International clinical practice guidelines for the treatment of acute uncomplicated cystitis and pyelonephritis in women: A 2010 update by the Infectious Disease Society of America and the European Society for Microbiology and Infectious Diseases. Clinical Infectious Diseases, 52(5): e103-e120.

Iroha, I.R., Adikwu, M.U., Esimone, C.O., Aibinu, I. and Amadi, E.S. (2009). Extended spectrum beta-lactamase (ESBL) in E. coli isolated from a tertiary hospital in Enugu state, Nigeria. Pakistan Journal of Medical Sciences, 25(2): 279-282.

Kome, O., Osogho, V.O. and Nwankwo, C.P. (2019). Escherichia coli as possible agents of spread of multidrug resistance in Port Harcourt, Rivers State. Annals of Science and Technology, 4(1): 16-21.

Kumburu, H.H., Sonda, T., Mmbaga, B.T., Alifrangis, M., Lund, O., Kibiki, G. and Aarestrup, F.M. (2017). Patterns of infections, etiological agents, and antimicrobial resistance at a tertiary care hospital in northern Tanzania. Tropical Medicine and International Health, 22: 454-464.

Lal, P., Kapil, A., Das, B.K. and Sood, S. (2007). Occurrence of TEM \& SHV gene in extended spectrum $\beta$-lactamases (ESBLs) producing Klebsiella sp. isolated from a tertiary care hospital. Indian Journal of Medical Research, 125:173178.

Lensing, J., Vilankar, K., Hyojung, K., Donald, B., Amy, M. and Laura, B (2017). Environmental reservoirs of nosocomial infection: Imputation method for linking clinical and environmental microbiological data to understand infection transmission. AMIA Annual Symposium Proceedings, 11201129 .

Liu, W., Chen, L., Li, H., Duan, H. and Zhang, Y. (2009). Novel CTX-M beta-lactamase genotype distribution and spread into multiple species of Enterobacteriaceae in Changsha, Southern China. Journal of Antimicrobial Chemotherapy, 63: 895-90. 
Mahamat, O.O., Lounnas, M., Hide, M., Dumon,t Y., Tidjani, A., Kamougam, K., Abderrahmane, M., Benavides, J., Solassol, J., Bañuls, A., Jean-Pierre, H., Carrière, C. and Godreuil, S. (2019). High prevalence and characterization of extended-spectrum $\quad \beta$-lactamase $\quad$ producing Enterobacteriaceae in Chadian hospitals. BioMed Central, 19(1): 205.

Mbanga, J., Dube, S. and Munyanduki, H. (2010). Prevalence and drug resistance in bacteria of the urinary tract infections in Bulawayo province, Zimbabwe. East African Journal of Public Health, 7: 229-232.

Muhammad, M.H. and Swedan, S. (2015). Molecular and phenotypic characterization of carbapenem resistance and extended spectrum beta-lactamase among urinary Escherichia coli isolates. International Journal of Science and Technology, 5(9): 1-9.

Muluye, D., Wondimeneh, Y., Ferede, G., Nega, T., Adane, K., Biadgo, B., Tesfa, H. and Moges, F. (2014). Bacterial isolates and their antibiotic susceptibility patterns and patients with pus and/or wound discharge at Gondar University hospital. BMC Research Notes, 7: 619-624.

Nedjai, S., Barguigua, A., Djahmi, N., Jamali, L., Zerouali, K., Dekhil, M. and Timinouni, M. (2013). Prevalence and characterization of extended spectrum beta-lactamaseproducing Enterobacter cloacae strains in Algeria. Journal of Infection in Developing Countries, 7(11):804-811.

Nordmann, P., Dortet, L. and Poirel, L. (2002). Carbapenem resistance in Enterobacteriaceae: Here is the storm! Trends in molecular medicine, 18(5): 263-272.

O'Neill J. (2015). Review on Antimicrobial Resistance. Tackling a crisis for the Health and Wealth of Nations. Review on Antimicrobial Resistance, United Kingdom, pp. $1-16$.

Ogefere, H.O., Aigbiremwen, P.A. and Omoregie, R. (2015). Extended Spectrum Beta-Lactamase (ESBLs) producing Gram-negative isolates from urine and wound specimens in a tertiary health facility in southern Nigeria. Tropical Journal of Pharmaceutical Research, 14(6): 1089-1094.

Okesola, A.O. and Adeniji, T.W. (2010). Pattern of extendedspectrum beta-lactamase production among clinical isolates of Proteus species in Western Nigeria. World Journal of Medical Science, 5: 94-97.

Oluduro, A.O., Aregbesola, O.A. and Fashina, C.D. (2014) Extended Spectrum Beta-lactamase Producing Uropathogenic Escherichia coli in Pregnant Women Diagnosed with Urinary Tract Infection in South-Western Nigeria. Journal of Molecular Biology Research, 4(1): 34-41. Onanuga, A., Mahindroo, J., Singh, S. and Taneja, N. (2019). Phenotypic and molecular characterization of antimicrobial resistant Escherichia coli from urinary tract infections in Port-Harcourt, Nigeria. Pan African Medical Journal, 34: 144.

Pai, H., Choi, E.H., Lee, H.J., Hong, J.Y. and Jacoby, G.A. (2001). Identification of CTX-M-14 extended-spectrum beta lactamase in clinical isolates of Shigella sonnei, Escherichia coli and Klebsiella pneumonia in Korea. Journal of clinical microbiology, 39: 3747-3749.

Pitout, J.D. and Laupland, K.B. (2008). Extended-spectrum $\beta$-lactamase-producing Enterobacteriaceae: an emerging public-health concern. Lancet Infectious Diseases, 8(3): 159166.

Raji, M.A., Jamal, W., Ojemeh, O. and Rotimi, V.O. (2015). Sequence analysis of genes mediating extended-spectrum beta-lactamase (ESBL) production in isolates of Enterobacteriaceae in Lagos teaching hospital, Nigeria. BMC Infectious Disease, 15: 259.

Reta, A., Kifilie, A.B. and Mengist, A. (2019). Bacterial infections and their antibiotic resistance pattern in Ethiopia: A systematic review. Advances in Preventive Medicine, 2019: 1-10.

Shaikh, S., Fatima, J., Shakil, S., Mohd, R. and Kamal, M.A. (2015). Antibiotic resistance and extended spectrum betalactamases: Types, epidemiology and treatment. Saudi Journal of Biological Sciences, 22(1): 90-101.

Song, W., Lee, K.M., Kang, H.J., Shin, D.H. and Kim, D.K. (2001). Micrologic aspects of predominant bacteria isolated from the burn patients in Korea. Burns, 27: 136-139.

Stadler, T., Meinel, D. and Aguilar-Bulet, L. (2018). Transmission of ESBL-producing Enterobacteriaceae and their mobile genetic elements. Identification of sources by whole genome sequencing: Study protocol for an observational study in Switzerland. BMJ Open, 8: e021823.

Teklu, D.S., Negei, A.A., Legese, M.H., Badada, T.L., Woldermariam, H.K. and Tellu, D.K. (2019). Extendedspectrum beta-lactamase production and multi-drug resistance among Enterobacteriaceae isolated in Addis Ababa, Ethiopia. Antimicrobial Resistance and Infection control, 8(1): 39.

Vaidya, V.K. (2011). Horizonal Transfer of Antimicrobial Resistance by Extended Spectrum $\beta$ Lactamase-Producing Enterobacteriaceae. Journal of Laboratory Physicians, 3(1): $37-42$.

Warren, J.W., Abrulyn, E., Habel, J.R., Johnson, J.R., Schaeffer, A.J. and Stamm, W.E. (1999). Guidelines for antimicrobial treatment of uncomplicated acute bacterial cystitis and acute pyelonephritis in women. Clinical Infectious Disease, 29: 745-759. 
Woerther, P.L., Burdet, C., Chachaty, E. and Andremont, A. (2013). Trends in Human Faecal Carriage of ExtendedSpectrum $\beta$-Lactamases in the Community: Toward the Globalization of CTX-M. Clinical Microbiology Reviews, 26: 744-758.

World Health Organization (2014). Antimicrobial resistance: global report on surveillance.

World Health Organization (2017). Global Priority List of Antibiotic-Resistant Bacteria to Guide Research, Discovery, and Development of New Antibiotics.

Yusuf, I., Haruna, M. and Yahaya, H. (2013). Prevalence and antibiotic susceptibility of ampc and ESBL producing clinical isolates at a tertiary health care centre in Kano, Northwest Nigeria. African Journal of Clinical and Experimental Microbiology, 14(2): 109-119.

Zaman, M.A., Pasha, M.H. and Akhter, M.Z. (2010). Plasmid curing of Escherichia coli cells with etidium bromide, sodium dodecyl sulfate and acridine orange. British Medical Journal 27: 28-31.

Zykov, I.N., Sundsfjord, A., Smabrekke, L. and Samuelsen, O. (2016). The antimicrobial activity of mecillinam, nitrofurantoin, temocillin and Fosfomycin and comparative analysis of resistance patterns in a nationwide collection of ESBL-producing Escherichia coli in Norway 2010-2011. Infectious Diseases, 48(2): 99-107. 